\title{
Positron Emission Tomography (PET) in Differentiating Manganism from Idiopathic Parkinsonism
}

\author{
Yangho KIM ${ }^{1}$, Jae-Woo $\mathrm{KIM}^{2}$, Kengo $\mathrm{ITO}^{3}$, Naomi HisanaGA ${ }^{4}$, Hae-Kwan $\mathrm{CHeONG}^{5}$, \\ Kyoo Sang KIM ${ }^{1}$ and Younghahn Moon $^{1}$
}

' Industrial Health Research Institute, Korea Industrial Safety Corporation (KISCO), ${ }^{2}$ Department of Neurology, Dong-A University Hospital, ${ }^{3}$ Department of Biofunction Research, National Institute for Longevity Sciences, Obu, ${ }^{4}$ National Institute of Industrial Health and ${ }^{5}$ Department of Preventive Medicine, College of Medicine, Dongguk University

\begin{abstract}
Positron Emission Tomography (PET) in Differentiating Manganism from Idiopathic Parkinsonism: Yangho Kıм, et al. Industrial Health Research Institute, Korea Industrial Safety Corporation (KISCO) - It is difficult to distinguish manganism and idiopathic parkinsonism from each other, especially in the settings where an isolated patient with parkinsonism has spent time in a manganese $(\mathrm{Mn})$-exposed working environment. We performed clinical examinations and laboratory studies including mangetic resonance imaging (MRI) and positron emission tomography (PET) in two $\mathrm{Mn}$ exposed workers (cases 1 and 2) who had parkinsonian features. The clinical features of case 1 , however, were rather different from those of case 2, although both of them have some common parkinsonian features such as bradykinesia, tremor and rigidity. MRI in case 1 showed no abonormaities, but in case 2 showed symmetrical high signal intensities in the globus pallidus on a T1 weighted image. On PET findings, Ki values in the striatum were within the normal range in case 1 , but reduced ${ }^{18} \mathrm{~F}-6$-fluorodopa uptake in the left putamen was seen in case 2. PET provides information of considerable value in discriminating between idiopathic parkinsonism and mangnism.

(J Occup Health 1999; 41: 91-94)
\end{abstract}

Key words: ${ }^{18} \mathrm{~F}-6$-fluorodopa, High signal intensities, Magnetic resonance image, Manganism, Idiopathic parkinsonism, Manganese exposure, Positron emission tomography

The diagnosis of manganese $(\mathrm{Mn})$ poisoning in industrial workers can usually be made when an

Received June 26, 1998; Accepted Jan 20, 1999

Correspondence to: $Y$. Kim, Industrial Health Research Institute,

Korea Industrial Safety Corporation (KISCO), Kusan-Dong, Bupyeng-Ku, Incheon 403-711, South Korea extrapyramidal symptom complex such as parkinsonism develops in workers exposed to $\mathrm{Mn}$. The clinical features of manganism are, however, similar to those of idiopathic parkinsonism. As workers work until older ages than in the past, they are more liable to get neurodegenerative diseases such as idiopathic parkinsonism during their active working lifetime. It is therefore difficult to distinguish manganism and idiopathic parkinsonism from each other, especially in settings in which an isolated patient with parkinsonism has spent time in a Mn-exposed working environment, although the differential diagnosis is somewhat easier in the context of outbreaks.

We report the similarities and differences between a case of idiopathic parkinsonism with superimposed manganesc exposure and a case of manganism, and discuss the value of ${ }^{18} \mathrm{~F}$-6-fluorodopa $\left({ }^{18} \mathrm{~F}\right.$-dopa) positron emission tomography (PET) in differential diagnosis.

\section{Patients and methods}

A patient with remote exposure to $\mathrm{Mn}$ (case 1), a 51year-old male, is one of six well-documented cases of manganism who had worked in the same factory employing about 20 workers over 10 years ago ${ }^{1)}$. They had prepared manganese powder for welding rods by crushing ferromanganese and treated the rods with acid or alkali. Six workers had complained of symptoms similar to parkinsonian features. The patient had worked for one year in the factory and had quit the job because of tremors and gait disturbances in 1985 . Since then he has had no exposure. Out of six workers, one died, and two are in a bed-ridden state because of secondary complications such as hip fracture or head trauma without showing such typical neurologic symptoms as at the first diagnosis of manganism. One could not be followed up, and the remaining two workers still showed such typical neurologic symptoms as they complained of at the diagnosis of 
manganism. Case 1 is one of the remainder.

A patient with recent exposure to $\mathrm{Mn}$ (case 2), a 48 year-old male, had been a welder for over 10 years. He had welded at several workplaces for two hours daily for 10 years, and in the latest workplace for 10 hours a day for the last two years. He had quit the job due to neurologic deficits such as tremors and rigidity in 1996, and had no exposure thereafter.

Blood and urinary Mn was measured by flameless atomic absorption spectrometry (Varian SpectraA $\Lambda$, Varian Techtron Pty, Victoria, Australia).

We performed magnetic resonance imaging (MRI) scan on case 1, 12 years after the cessation of exposure to $\mathrm{Mn}$, and on case 2 at the time of both 10 days and six months after the cessation of exposure.

PET scans were performed as follows;

The patients werc given $100 \mathrm{mg}$ of oral carbidopa one hour before scanning. The PET scan was performed with an ECAT EXACT HR (Siemens/CTI, Knoxville, Tenn., USA). Images were reconstructed by filtered backprojection, resulting in 47 slices with a $128 \times 128$ matrix (pixel size $1.8 \mathrm{~mm}$ ) and interplane separation of $3.125 \mathrm{~mm}$. Correction for tissue attenuation of $511 \mathrm{keV}$ gamma radiation was measured with an external Ge-68 ring. ${ }^{18} \mathrm{~F}$ dopa $(207 \mathrm{mBq})$ in a normal saline solution was infused intravenously for 30 seconds. Scanning began at the start of the tracer infusion with a protocol of 25 time frames (4 $\times 1 \mathrm{~min}, 3 \times 2 \mathrm{~min}, 3 \times 3 \mathrm{~min}, 15 \times 5 \mathrm{~min}$ ) for 94 minutes.

Analysis of data was performed on SUN workstations (Sun Microsystems, Silicon Valley, CA., USA). The parametric images of the ${ }^{18} \mathrm{~F}$-dopa influx constant $(\mathrm{Ki})$ were created with in-house software (MRC Cyclotron Unit, Hammersmith Hospital, London, UK) written in IDL image analysis software (Research Systems, Inc., Boulder, CO, USA) based on the MTGA (multiple-time graphical analysis) approach of Patlak and Blasberg ${ }^{2,3)}$. We used the time frames from 25 to $94 \mathrm{~min}$ post-injection with occipital counts as the input function. ROI (region of interest) analysis was performed on the $\mathrm{Ki}$ images. The ROIs were placed on three contiguous planes containing caudate and putamen by image inspection with reference to the stereotactic atlas of Talairach and Tournoux ${ }^{4}$. One circular ROI of $63.6 \mathrm{~mm}^{2}$ (diameter $=9$ $\mathrm{mm}$ ) was positioned by inspection on each caudate nuclcus. One elliptical $152.6 \mathrm{~mm}^{2} \mathrm{ROI}$ was placed on each putamen.

\section{Results \\ Patients}

Onc patient with remote exposure to Mn (case 1) and the other with recent exposure (case 2) have showed some common parkinson-like features such as bradykinesia, tremors and rigidity in the present neurologic examination (Table 1). Case 1 showed severe postural instability, the so called "cock walk", turning difficulty and a particular propensity to fall in backward gait. Severe action tremor in both hands and dystonia in his left hand was remarkable. At first he showed a mild response to levodopa, which was not sustained. Compared with previous symptom and signs, those seen at present had not been aggravated for 12 years. Clinical features of case 2 , howcver, were rather different from those of case

Table 1. Occupational histories, and clinical and laboratory features of two workers exposed to manganese (Mn)

\begin{tabular}{|c|c|c|}
\hline & Case 1 & Case 2 \\
\hline Age/gender & $52 /$ male & $49 /$ male \\
\hline Occupation & $\begin{array}{l}\text { preparing of } \mathrm{Mn} \text { powder for welding } \\
\text { rods by crushing ferromanganese }\end{array}$ & welding \\
\hline Mn exposure period & $1984.11-1985.10$ & $1988.1-1996.10$ \\
\hline Onset (age) & $1985.9(39)$ & $1996.9(47)$ \\
\hline $\begin{array}{l}\text { Simultaneous occurences } \\
\text { in fellow workers }\end{array}$ & 5 out of 20 workers & none out of 21 workers \\
\hline Common clinical features & \multirow{2}{*}{\multicolumn{2}{|c|}{ tremor, rigidity, bradykinesia }} \\
\hline Differences in clnical features & & \\
\hline bilaterality & right>left & right side only \\
\hline gait disturbance & + & - \\
\hline dystonia & + & - \\
\hline tremor & resting<action & resting $>$ action \\
\hline $\begin{array}{l}\text { High signal intensities } \\
\text { in T1-weighted image (MRI) }\end{array}$ & $\begin{array}{l}-; 12 \text { years after the cessation of the } \\
\text { exposure to } \mathrm{Mn}\end{array}$ & $\begin{array}{l}+; 10 \text { days after the cessation } \\
-; 6 \text { months after the cessation }\end{array}$ \\
\hline \multicolumn{3}{|l|}{ Ki value in PET } \\
\hline caudate & right; $0.0120 / \mathrm{min}$ & right; $0.0122 / \mathrm{min}$ \\
\hline reference; $0.0099-0.0151 / \mathrm{min}$ & left; 0.0127 & left; 0.0106 \\
\hline putamen & right; $0.0123 / \mathrm{min}$ & right; $0.0105 / \mathrm{min}$ \\
\hline reference; $0.0087-0.0163 / \mathrm{min}$ & left; 0.0124 & left; 0.0059 \\
\hline
\end{tabular}


1. Case 2 had developed progressive resting tremor in his right arm one year earlier and right leg resting tremor three months later. He had a masked facc and bradykinesia. He was found to have a predominant resting tremor of the right arm and leg, and rigidity of the right wrist and elbow on neurologcial examination, but had no signs of dystonia or gait disturbance. Tremor and rigidity improved slightly with levodopa.

\section{Laboratory findings}

The blood and urine $\mathrm{Mn}$ concentrations analyzed after two months of cessation of exposure were $3.26 \mu \mathrm{g} / \mathrm{d} l$ and $3.57 \mu \mathrm{g} / l$ (normal $<2 \mu \mathrm{g} / \mathrm{d} l$ and $2 \mu \mathrm{g} / l$, respectively) ${ }^{5)}$ in case 2 . The urinary $\mathrm{Mn}$ concentration $(73.3 \mu \mathrm{g} / \mathrm{day})$ obtained after treatment with $1 \mathrm{~g}$ EDTA IV had increased significantly compared to the prechelation level of 13.6 $\mu \mathrm{g} /$ day. There was, however, no significant increase in urinary cadmium or lead concentrations. And the mean level of exposure to $\mathrm{Mn}$ fumes for other welders in the factory where case 2 worked was $0.63 \mathrm{mg} / \mathrm{m}^{3}$, but wc

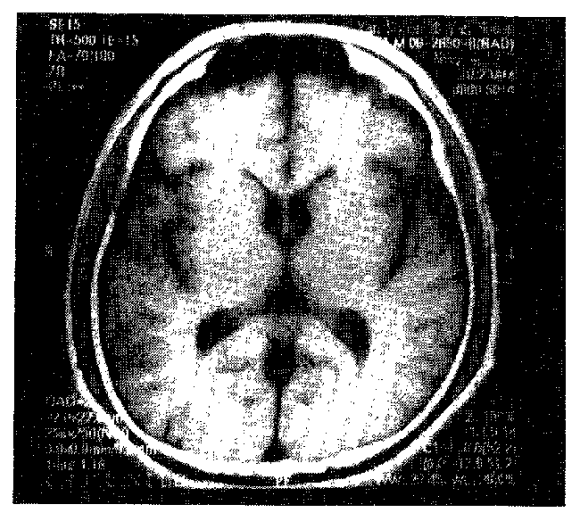

Fig. 1. T1 weighted MRI images of case 1 showing no signal changes.



Fig. 3. PET scan showed normal ${ }^{18} \mathrm{~F}$-dopa uptake in the striatum (case 1). had no biological monitoring data for case 1.

MRI showed no abonormalities in case 1 (Fig. 1), but there were symmetrical high signal intensities in the globus pallidus on a T1 weighted image in case 2 (Fig. 2). T2 signals were unremarkable. Repeated MRI six months after the first one showed almost complete resolution of the high signal intensities in the globus pallidus (Fig. 2).

$\mathrm{Ki}$ values in the striatum on PET scan are shown in Table 1.

$\mathrm{Ki}$ values in the striatum were within the normal range in case 1, but were reduced in the left putamen in case 2 . PET scan showed normal ${ }^{18} \mathrm{~F}$-dopa uptake in the striatum in case 1 (Fig. 3) and reduced ${ }^{18}$ F-dopa uptake in the left putamen in case 2 (Fig. 4).

\section{Discussion}

Mn exposure histories in the workplace, the temporal relationship between the exposure and onset of symptoms and signs, and simultaneous development of similar diseases in fellow workers in the same factory strongly


Fig. 2. T1-weighted MRI images of case 2 showing high signal intensities in the globus pallidus, arrow (left). High signal intensities have resolved in 6 months after withdrawal of Mn (right).
Fig. 4. PET scan showed reduced ${ }^{18} \mathrm{~F}$-dopa uptake in the left putamen (case 2). 
suggest that the parkinsonian features in case 1 were induced by Mn. Case 1 showed typical neurologic features such as severe postural instability, a particular propensity to fall in backward gait, the so-called cock walk, predominant action tremor, and dystonia at first, which are frequently observed in manganism. The clinical signs were sustained after the cessation of exposure to Mn. Occupational history, a mild increase in the blood and urine Mn concentrations, and a significant increase in the urinary Mn concentration after EDTA treatment indicate overexposure to $\mathrm{Mn}$ in case 2 . The clinical signs in case 2 were compatible with parkinsonism, but predominant unilateral resting tremor and lack of gait disturbance or dystonia can be compared to the clinical features in case 1 , frequently observed in manganism ${ }^{6}$. These clinical features in case 2 suggest idiopathic parkinsonism, although it is somewhat difficult to make a final diagnosis with clinical signs only.

Experimental $\mathrm{Mn}$ poisoning of the primate, a $\mathrm{Mn}$ overload of prolonged total parenteral nutrition or chronic liver discase produces symmetrical high signal intensities in the basal ganglia, midbrain and pons in $\mathrm{T} 1$ weighted MRI of the brain ${ }^{7-9)}$. Resolution of this signal, usually within six months, reflects clearance of $\mathrm{Mn}$ from the brain despite permanent neurological damage ${ }^{8,10,11)}$. The two MRI findings in case 2 showed exposure to $\mathrm{Mn}$ and clearance of $\mathrm{Mn}$ from the brain. A normal MRI result in case 1 is also reasonable considering the long term cessation of exposure. These findings suggest that high signal intensities on T1weighted image reflect current exposure to $\mathrm{Mn}$.

${ }^{18} \mathrm{~F}$-dopa PET provides an index of the integrity of the dopaminergic nigrostriatal pathway, the primary focus of neurodegeneration in idiopathic parkinsonism, and is abnormal in idiopathic parkinsonism ${ }^{3,12,13)}$. There is reduced uptake in the striatum, particularly the posterior putamen $^{6}$. This finding is in accord with the knowledge that there is a 40 to $60 \%$ loss of dopaminergic cells in the nigrostriatal pathway. In nonhuman primates that had been intoxicated with $\mathrm{Mn}$, the ${ }^{18} \mathrm{~F}$-dopa PET scan was normal ${ }^{14}$ 15), compatible with the pallidum being the epicenter of damage induced by manganese. PET findings in human manganism arc, however, limited to a group of four cases in a Taiwanese ferromanganese smelting plant ${ }^{16}$. The PET findings in case 1 showed normal ${ }^{18} \mathrm{~F}$-dopa uptake in the striatum, as shown in the Taiwanese manganism cases. This result indicated that in manganism there are normal PET findings. PET scan in case 2, however, showed reduced ${ }^{18} \mathrm{~F}$-dopa uptake in left putamen. This finding with such clinical features as predominent unilateral resting tremor, and lack of gait disturbance or dystonia shows that casc 2 is one of idiopathic parkinsonism with superimposed manganese exposure. We therefore should be prudent in diagnosing an isolated parkinsonism case as manganism even though the patient has definitely been exposed to $\mathrm{Mn}$. These results indicate that PET provides information of considerable value in differentiating manganism from idiopathic parkinsonism.

\section{References}

1) Lim Y, Yim H W, Kim K A, Yun I G. Review on manganse poisoning. Korean J Occup Health 1991; 30: 13-18.

2) Patlak CS, Blasberg RG, Fenstermacher JD. Graphical evaluation of blood-to-brain transfer constants from multiple-time uptake data. J Cereb Blood Flow Metab 1983; 3: 1-7.

3) Brooks DJ, Salmon EP, Mathias CJ, et al. The relationship between locomotor disability, autonomic dysfunction, and the integrity of the striatal dopaminergic system in patients with multiple system atrophy, pure autonomic failure and Parkinson's disease, studied with PET. Brain 1990; 113: 1539-1552.

4) Talairach J, Tournoux P: Coplanar stereotaxic atlas of the human brain. New York: Georg Thieme Verlag, 1988.

5) World Health Organization. Early detection of occupational diseases. Geneva: World Health Organization, 1986; pp 69-73.

6) Calne DB, Chu NS, Huang CC, Lu CS, Olanow W. Manganism and idiopathic parkinsonism: similarities and differences. Neurology 1994; 44: 1583-I586.

7) Mirowitz SA, Westrich TJ, Hirsch JD. Hyperintense basal ganglia on T1-weighted MR images in patients receiving parenteral nutrition. Radiology 1991; 181: $117-120$.

8) Ejima A, Imamura T, Nakamura S, Saito H, Matsumoto $\mathrm{K}$, Momono S. Manganese intoxication during total parental nutrition. Lancet 1992; 339: 426.

9) Krieger D, Krieger S, Jansen O, Gass P, Theilmann L, Lichtnecker H. Manganese and chronic hepatic encephalopathy. Lancet 1995; 346: 270-274.

10) Newland MC, Ceckler TL, Kordower JH, Weiss B. Visualizing manganese in the primate basal ganglia with magnetic resonance imaging. Exp Neurol 1989; 106: 251-258.

11) Nelson K, Golnick J, Korn T, Angle C. Manganese encephalopathy: utility of carly magnetic resonance imaging. Br J Ind Med 1993; 50: 510-513.

12) Morrish PK, Sawle GV, Brooks DJ. Clinical and $\left[{ }^{18} \mathrm{~F}\right]$ dopa PET findings in early Parkinson's disease. $J$ Neurol Neurosurg Psychiatry 1995; 59: 597-600.

13) Morrish PK, Sawle GV, Brooks DJ. An [18F]dopa-PET and clinical study of the rate of progression in Parkinson's disease. Brain 1996; 119: 585-591.

14) Eriksson H, Tedroff J, Thuomas KA, Aquilonius SM et al. Manganese induced brain lesions in Macaca fasciculularis as revealed by positron emission tomography and magnetic resonance imaging. Arch Toxicol 1992; 66: 403-407.

15) Shinotoh H Snow BJ, Hewitt KA, Pate BD et al. MRI and PET studies of manganese-intoxicated monkeys. Neurology 1995; 45: 1199-1204.

16) Wolters EC Huang CC, Clark C, Peppard RF et al. Positron emission tomography in manganese intoxication. Annals of Neurology 1989; 26: 647-651. 